\title{
Revolução budista ou apocalipse zumbi? Discussões sobre mindfulness a partir de uma perspectiva gestáltica
}

\author{
Fabio Nogueira Pereira* (1) \\ Carla Gomes Dalgolbo \\ Monalisa Oliveira da Silva (1)
}

Centro Universitário Faesa, Vitória, ES, Brasil

\begin{abstract}
Resumo: A busca por práticas meditativas orientais como tecnologia promotora de saúde e qualidade de vida tem aumentado significativamente nos últimos anos. Contudo percebe-se que a falta de compreensão dos conceitos e princípios dos quais emergem tais técnicas produzem propostas que podem ser tanto uma saída revolucionária quanto distópica. Propomos neste texto uma breve discussão sobre o movimento de mindfulness a partir de uma perspectiva gestáltica de influência goodmaniana. Assim, (a) apresentamos de maneira resumida a transmissão destas práticas desde tradições budistas até a ciência ocidental contemporânea; (b) destacamos alguns aspectos teóricos que aproximam e distanciam a Gestalt-terapia de pressupostos budistas; e (c) discutimos a apropriação dessas tradições, seus valores e suas tecnologias por um paradigma neoliberal utilitarista.
\end{abstract}

Palavras-chave: mindfulness, Gestalt-terapia, ideologia, saúde mental, política.

\section{Introdução}

A busca por práticas interventivas na área de saúde tem mobilizado profissionais e pesquisadores. Nesse contexto, alguns têm fomentado a adoção de novos paradigmas para a compreensão dos processos de adoecimento e o uso de terapias integrativas oriundas de culturas orientais. A apropriação cultural e de práticas terapêuticas, em especial do budismo em suas diversas variações, em prol do desenvolvimento de tecnologias e políticas de saúde parece distanciar a práxis de sua base ideológica, levando a uma aproximação do neoliberalismo, de tal forma que alguns já afirmam a comoditização do McMindfulness como nova religião neoliberal (Doran, 2018; Purser, 2019; Schmidt, 2016; Žižek, 2012). Essa decisão de manter uma abordagem neutra se basearia na premissa de que as ciências da saúde não poderiam sugerir ou prescrever tecnologias com vieses ideológicos ou religiosos, impondo um estilo de vida para pacientes, sobretudo por meio de políticas de saúde estatais (Schmidt, 2016).

A psicologia budista visa auxiliar o indivíduo a reconhecer os condicionantes de seu comportamento para que possa se libertar de automatismos funcionais, desenvolvendo atenção plena, a observação dos fenômenos sem julgamento e consciência do que se apresenta no presente de forma acolhedora e paciente (Batchelor, 1998, 2012; Fulton \& Siegel, 2016; Gold \& Zahm, 2018; Nhat Hahn, 1993; Olendzki, 2012). Por outro lado, tais práticas contemplativas também se referenciam na compreensão de que o indivíduo não tem controle

\footnotetext{
* Endereço para correspondência: fabionogueirapereira@gmail.com
}

total sobre o ambiente e tampouco está subjugado a ele, considerando um campo complexo multidimensional do qual os fenômenos emergem a partir de relações interdependentes (Batchelor, 1998, 2012; Gold \& Zahm, 2018; Nhat Hahn, 1993). A tecnologia oferecida pela psicologia budista tem como fundo a premissa de que tudo está interligado, o que nos leva a pensar que treinamentos corporativos de mindfulness em empresas que adotam políticas produtivas insalubres e exploratórias entram em confronto direto com pressupostos muito claros e bem estabelecidos nessa tradição, ao evidenciar apenas o treinamento da plena atenção focada num recorte de curto prazo e desconsiderar o reconhecimento de condicionantes presentes no campo mais abrangente e em longo prazo numa tentativa clara de manipular as pessoas (Brazier, 2016; Tomassini, 2016). Talvez o erro resida no fato de que parte de a psicologia ocidental foca no aspecto atencional e na redução de sintomas (Gold \& Zahm, 2018), bem como na individualização dos fenômenos em detrimento de uma compreensão de emergência interdependente (Tomassini, 2016).

A discussão que propomos se torna ainda mais relevante quando, além da banalização do método por pessoas que não se dedicam ao estudo do fundo a partir do qual as práticas emergem, a psicologia moderna ocidental apreende e endossa o uso dessas técnicas sem o devido cuidado com sua ancestralidade e seus efeitos individual e societal, contribuindo para a manutenção de uma sociedade egotista, insular e que nega sua animalidade, sua ambientalidade, sua historicidade e a inserção sustentável no campo como parte integrante e não dissociada da natureza e do tempo (Batchelor, 2012; Nhat Hahn, 1993). 
Este estudo se propõe como uma revisão bibliográfica narrativa crítica (Sousa, Firmino, Marques-Vieira, Severino, \& Pestana, 2018; Vosgerau \& Romanowski, 2014), uma vez que buscamos fazer uma breve apresentação da literatura sobre os fundamentos e o uso das técnicas consideradas dentro do termo guardachuva mindfulness, assim como dos pressupostos da filosofia oriental que permeiam tal prática e que podem estar sendo negligenciados. Tomamos a abordagem gestáltica como norteadora para repensarmos aspectos éticos quando da fundamentação de intervenções sob influência da psicologia budista e do uso da tecnologia a ela relacionada na psicoterapia. Acreditamos que essa discussão fomenta um contexto no qual as intervenções podem ser mais conscientes, recuperando as dimensões humanas, societais e ecológicas das relações estabelecidas e inspirando o engajamento no desenvolvimento comunitário sustentável.

\section{Psicologia budista: da tradição oriental à ciência ocidental contemporânea}

O desenvolvimento do Dharma (doutrina ou instruções em sânscrito) budista remonta a Sidharta Gautama há mais de 2.600 anos na Índia e acredita-se que ele teria falecido com aproximadamente 80 anos, por volta de 400 a.C., tendo ensinado várias pessoas por 45 anos (Batchelor, 2012; Gold \& Zahm, 2018; Scott \& Doubleday, 2001). A partir da Índia, o budismo percorreu a Ásia Central e chegou a outras partes do mundo nos séculos seguintes. Em cada território alcançado, acabou absorvendo alguns elementos culturais locais, o que contribuiu por tornar o budismo uma das principais religiões do mundo (Diniz, 2010; Scott \& Doubleday, 2001). Somente a partir da segunda metade do século XX começou a ser notado pela ciência ocidental, uma vez que já começava a chamar a atenção de pensadores há algumas décadas (Diniz, 2010; Germer, 2016).

Segundo os pressupostos da tradição budista, o sofrimento humano é proveniente da própria mente, da maneira como nos relacionamos conosco e com o mundo, e é explicada a partir de Quatro Verdades: (1) o sofrimento (sofrimento, insatisfação, incerteza, dor) é inerente à vida; (2) a origem do sofrimento está nos desejos provenientes do ego; (3) o sofrimento pode ser extinto ao se extinguir sua causa; e, (4) para extinguir o sofrimento, devemos seguir o Caminho Óctuplo (Batchelor, 1998; Cebolla \& Demarzo, 2016; Gold \& Zahm, 2018; Olendzki, 2012, 2016). Gautama, reconhecido por seus seguidores como Buda ou iluminado, teria ensinado a seus discípulos como poderiam se livrar do sofrimento a partir de uma metodologia que considera oito aspectos: compreensão correta, pensamento correto, fala correta, ação correta, meio de vida correto, esforço correto, consciência correta e concentração correta. Esse é o cerne da proposta budista para a extinção do sofrimento, sendo a prática de meditação (concentração correta) apenas um dos aspectos que precisam ser observados para a extinção do sofrimento (Frisk, 2012; Olendzki, 2016).

\section{Uma tecnologia desenvolvida ao longo de várias gerações}

No decorrer dos séculos, uma ampla variedade de técnicas de meditação foi sistematizada com o propósito de treinar e desenvolver as habilidades de atenção focada, de concentração, de questionamento da percepção de um eu permanente, entre outras. Dentre as possibilidades de treinamento oferecidas pela metodologia budista, iremos ater nosso debate ao uso do mindfulness, ou prática voltadas para a atenção plena, por ser este recorte o feito pela ciência ocidental em prol do desenvolvimento de tecnologias a serem oferecidas como soluções de saúde pública. $\mathrm{O}$ termo mindfulness é uma tradução na língua inglesa do termo pali sati ou sânscrito smrti na sistematização da psicologia budista há milênios. Diferentemente da noção traduzida no Ocidente, o termo sugere significados como estar atento, dar-se conta (awareness), atenção e lembrar (Frisk, 2012; Germer, 2016), ou seja, uma amplitude de fenômenos e atitudes além da compreensão de atenção presente e sem julgamentos (bare attention) comumente encontrada na literatura contemporânea. Na tradição budista, samma sati, ou concentração correta, é um ensinamento central; todavia o Caminho Óctuplo entrelaça todos seus elementos de maneira interdependente e a prática deveria se atentar para todos os oito aspectos descritos, pois eles se sustentam uns nos outros. Seria, nesta perspectiva, um erro incentivar o treino de apenas um deles, como temos observado no discurso ocidental.

Mindfulness é definida por várias escolas budistas como a faculdade mental de manter a atenção focada, sem esquecimento ou distração, em um dado objeto (Gold \& Zahm, 2018), não só de forma introspectiva como também voltada ao ambiente e a nossa relação com ele (Batchelor, 1998; Gold \& Zahm, 2018; Nhat Hahn, 1993). Tal estado de atenção plena é cultivado inicialmente por meio de práticas voltadas para samatha, ou atenção focada. Desenvolver a capacidade de permanecer atento a algo em contemplação (seja um objeto, uma sensação corporal, um pensamento ou uma emoção) é o primeiro passo para que se possa passar de fenômenos específicos para uma prática de monitoramento aberto, acolhendo os fenômenos emergentes ainda em contemplação, conhecida como vipassana (Frisk, 2012; Germer, 2016; Gold \& Zahm, 2018). O que se busca com ambas é o desenvolvimento da função de captação por meio da expansão da amplitude da atenção. A diferença reside na atenção focada em um único fenômeno em uma e a capacidade de alternar o foco de atenção conforme engajamos com o mundo na segunda (Germer, 2016; Gold \& Zahm, 2018). A prática de vipassana denota uma atitude mais investigativa que permita ver a real natureza da realidade ou dos fenômenos emergentes. Dentro do escopo 
das práticas de vipassana incluímos o cultivo de sati (atenção plena) e samadhi (concentração), além de outras mais voltadas para a adoção de atitudes para consigo mesmo e outros, como as práticas de metta (bondade amorosa) e karuna (compaixão) (Gold \& Zahm, 2018). A adoção de uma nova postura diante do que se apresenta permite ao praticante reconhecer os condicionantes de seu comportamento e relação com o mundo, de forma que não reaja mais automaticamente, mas podendo escolher como se portar levando em conta as condições presentes (Batchelor, 1998; Gold \& Zahm, 2018; Kabat-Zinn, 2017; Olendzki, 2012).

As práticas também podem ser classificadas de acordo com sua incorporação no cotidiano do praticante, sendo elas formais ou informais. As primeiras são baseadas em técnicas de meditação padronizadas e as últimas quando levamos essa atitude em atividades variadas no dia a dia (Cebolla \& Demarzo, 2016). Independentemente de a prática ser formal ou informal, elas podem ser realizadas, treinadas e aprendidas para que possamos lidar com as situações a partir de uma postura contemplativa, de acolhimento e não julgamento. Esta atitude plenamente presente vai de encontro com o modo de vida da sociedade ocidental contemporânea, no qual somos estimulados a automatizar nossos comportamentos e nos comportarmos em modo multitarefa (Han, 2017), ou seja, uma incongruência notória entre importantes valores basilares desses arcabouços culturais. Tomando nossa cultural ocidental como referência, isso poderia soar como colocar-se de forma passiva diante do que se apresenta; contudo o objetivo é justamente o contrário, de retomada do engajamento com as atividades mais atentos às variáveis contextuais que condicionam a relação que estabelecemos com o mundo (Demarzo \& Campayo, 2015; Fulton \& Siegel, 2016; Girard \& Feix, 2016; Gold \& Zahm, 2018).

\section{Adaptando práticas tradicionais a novos paradigmas}

As práticas tradicionais formais budistas foram adaptadas por profissionais da área da saúde principalmente a partir da década de 1970. Desde o surgimento de programas de mindfulness ocidentais, o movimento tem ganhado força no contexto clínico da psicologia e na promoção de saúde mental, sendo associados a diversas escolas psicoterápicas (Frisk, 2012; Fulton \& Siegel, 2016; Germer, 2016; Gold \& Zahm, 2018). Pioneiro na estruturação de um programa em 1979, Kabat-Zinn passou a utilizar adaptações de práticas budistas e yoguicas com pacientes acometidos de dores crônicas a fim de diminuir o estresse gerado por essa condição no programa Mindfulness Based Stress Reduction (MBSR) na Universidade de Massachusetts (Brown, 2016; Frisk, 2012; Kabat-Zinn, 2011). O MBSR foi utilizado como o principal programa de treinamento para pesquisas psicológicas, cuja inovação era ensinar que sensações e emoções negativas não deveriam ser combatidas, mas acolhidas, aceitas a partir de um novo prisma (Brown, 2016; Germer, 2016; Girard \& Feix, 2016). Estudos com populações diversas sugerem a eficácia do MBSR em pessoas com depressão, ansiedade e dor crônica, despertando o interesse por mais pesquisas na área e o desenvolvimento de protocolos para outras populações (Cebolla \& Demarzo, 2016; Fulton \& Siegel, 2016; Germer, 2016). Vários tipos de terapias baseadas em mindfulness têm sido desenvolvidos nas últimas décadas, porém nem sempre são discutidas as implicações de seus pressupostos filosóficos e teóricos ou os desdobramentos e efeitos após a participação em treinamentos de atenção plena (Brown, 2016; Schmidt, 2016).

Apesar de a Gestalt-terapia ter como fundo epistemológico filosofias orientais e alguns psicoterapeutas incluírem práticas meditativas em suas intervenções, são raras as tentativas de delinear mais claramente o diálogo entre as duas tradições (Gold \& Zahm, 2018; Naranjo, 1980, 2005, 2013; Rosmaninho, 2010; Veras, 2005, 2013) ou propor um treinamento específico em Gestalt-terapia que inclua aspectos da psicologia budista de maneira mais evidente e sistematizada (Gold \& Zahm, 2018; Naranjo, 2005). Nossa impressão é que isto possa ter ocorrido por descuido dos desenvolvedores originais da abordagem em demonstrar o aporte destas tradições no seu construto teórico-prático, assim como um privilégio dado aos filósofos ocidentais por um enviesamento colonialista. Esta discussão merece atenção da comunidade gestáltica internacional. A seguir, apresentaremos brevemente alguns aspectos epistemológicos e teóricos da Gestaltterapia em diálogo (ou não) com a psicologia budista. Nosso intuito não é esgotar uma descrição comparativa das duas tradições, mas unicamente explicitar ao leitor os elementos que utilizamos neste breve debate a fim de delinear nosso posicionamento mediante o movimento de mindfulness contemporâneo.

\section{Gestalt-terapia e psicologia budista: uma perspectiva de diálogo e crítica}

A Gestalt-terapia surgiu em meados do século XX propondo uma nova visão de homem sob influências diversas a partir da publicação do livro Gestalt Therapy, quando o termo foi utilizado pela primeira vez (Frazão, 2013; Juliano, 2004; Perls, 1994; Stoehr, 1991, 1994). Em Ego, fome e agressão, o casal Perls usou o termo "terapia de concentração", a fim de denotar a importância de se estar presente (Perls, 1994). Laura Perls (1994) endossa que, já em 1936, ela e Fritz tinham a intenção de revisar a teoria e a metodologia psicanalíticas e, anos mais tarde, na África do Sul, evidenciava-se o distanciamento e o rompimento para surgir uma nova proposta.

As opiniões eram divergentes entre os desenvolvedores iniciais desta escola quanto a aspectos teóricos, técnicos e também ao seu batismo (Perls, 1994; Stoehr, 1991): Ralph Hefferline propôs que se chamasse "terapia integrativa"; em oposição à associação livre da 
psicanálise, Fritz Perls queria nomeá-lo como "terapia da concentração"; o grupo em sua maioria, contudo, preferiu "terapia experiencial". Laura Perls se opôs ao nome "Gestalt-terapia" devido a seu conhecimento sobre Psicologia da Gestalt, e não achava apropriada a associação, de forma que preferia batizar a nova abordagem de "terapia existencial", porém também receava possíveis aproximações com autores como Sartre e o movimento niilista (Perls, 1994). Laura Perls (1994) declarou que não sabia precisar quem de fato nomeou a nova metodologia, sendo Fritz ou Paul Goodman quem teria sugerido o termo Gestalt-terapia; entretanto, divergências à parte, fica evidenciada a importância dada pelos desenvolvedores para a presentificação e o estabelecimento de relações conscientes (Prestrelo \& Quadros, 2009). A ideia era possibilitar ao paciente voltar-se para sua existência, sua relação consigo e com o mundo, a fim de retomar suas condições de escolha numa dada situação.

Nesse sentido, um dos pontos mais importantes era a noção de que o que o paciente faz da sua vida se torna um ajustamento criativo que não deve ser patologizado pelo terapeuta (Belmino, 2015, 2017; Gold \& Zahm, 2018; Spagnuolo Lobb, 2013). Não cabe ao Gestaltterapeuta levar o paciente para um padrão "normal", "saudável" ou "maduro" de comportamento, mas ajudá-lo a se reapropriar da espontaneidade e reconhecer sua capacidade criativa (Spagnuolo Lobb, 2013), promovendo sua autonomia (Belmino, 2017).

É possível encontrar autores que defendam a ideia de que Paul Goodman, com toda sua experiência em escrita e vasto conhecimento em filosofia fenomenológica, existencial, pragmatismo, budismo e taoísmo, bem como em psicologia e psicanálise, acabou por ser o principal responsável pela caracterização e estabelecimento da Gestalt-terapia enquanto nova abordagem psicoterapêutica (Sá, 2009) ou uma perspectiva ontológica que incide sobre a clínica, a política e a educação, entre outras esferas da vida (Belmino, 2017; Stoehr, 1991). O ecletismo de Goodman ao tecer a trama que sustenta a Gestalt-terapia se justifica pelo fato de ele ser um crítico da cultura de especialização do conhecimento (Belmino, 2017).

Goodman (2010b), com sua visão crítica diante do contexto social de sua época, acreditava que a sociolatria, tanto dos modelos capitalistas quanto socialistas, e a repressão social estavam distanciando as pessoas cada vez mais das necessidades básicas da natureza humana e das possibilidades participativas de negociação da organização social. Ele acreditava na capacidade de ajustamento criativo diante das várias formas de coerção e alienação dos desejos humanos na sociedade ocidental (Belmino, 2017, 2018; Goodman, 2010a, 2010b; Stoehr, 1991). Na compreensão desse autor, a polarização entre ceder às normas sociais para se tornar "uma pessoa bem ajustada" ou resguardar o aspecto anímico e dar as costas à sociedade deveria ser superada numa integração contínua dessas alternativas, acolhendo as diferenças e as variações de experiências, enfrentando a tensão e os conflitos da vida (Belmino, 2017, 2018; Goodman, 1991; Stoehr, 1991, 1994) e incluindo aspecto sociais, culturais e políticos (Belmino, 2017; Gold \& Zahm, 2018; Spagnuolo Lobb, 2013). Isso não é algo que parece ser enfatizado na psicologia ocidental contemporânea como originalmente é na psicologia budista (Gold \& Zahm, 2018).

Desde o princípio, devido à sua preocupação com os desdobramentos sociais de sua produção literária, sua atividade política e, por que não dizer, de sua breve experiência como psicoterapeuta, Paul Goodman buscou uma Gestalt-terapia considerando seu viés político. Assim, Goodman apresenta no livro Gestalt Therapy (Perls, Hefferline \& Goodman, 1997) uma abordagem de psicologia social num sentido lato, de uma clínica com implicações ampliadas, ou uma "socioterapia", como descreve Sá (2009). Essa deveria, portanto, ir além da polarização do psicologismo ou do sociologismo. Tal proposta é uma leitura fenomenológica da experiência que estudasse as inovações criadas para lidar com os conflitos entre organismo e ambiente, isto é, os ajustamentos criativos (Belmino, 2015, 2017, 2018; Goodman, 1991; Stoehr, 1994).

\section{Dialogando aproximações e distanciamentos}

Um ponto importante de diferenciação entre Gestalt-terapia e psicologia budista é a compreensão da relação que temos com os fenômenos presentes. $\mathrm{Na}$ abordagem gestáltica, o foco claramente é no enriquecimento da awareness, o que facilitaria a identificação e uma maior conexão com a experiência presente, o que destaca a função egoica no agenciamento de atos. A psicologia budista, por sua vez, incentiva o aumento da conscientização das emergências para deixar mais clara a interdependência dos fenômenos. Esta busca ir além do aspecto egóico, desconstruindo a percepção de um eu fixo e reconhecendo o fenômeno egoico uma produção impermanente em um amplo campo contingencial (Gold \& Zahm, 2018; Joyce \& Sills, 2016; Nhat Hahn, 1993). Claramente podemos observar na psicologia budista um direcionamento para a desconstrução da noção de eu centralizado, sólido ou reificado em favor de uma perspectiva de originação despessoalizada, insubstancial e mais ampla (Batchelor, 1998; Gold \& Zahm, 2018; Nhat Hahn, 1993).

Mesmo que a Gestalt-terapia tenha divergências com a psicologia budista, é inegável a aproximação (Gold \& Zahm, 2018; Veras, 2005, 2013) e uma possível complementação (Gold \& Zahm, 2018) dessas perspectivas. O objetivo de ambas extrapola o ôntico a fim de enfatizar o ontológico (Barrett, 1956; Veras, 2005, 2013). De tal modo, priorizam esse aspecto de forma que as intervenções e as práticas são experienciais e focam na apropriação da existência, de sua transformação e da transcendência humana (Gold \& Zahm, 2018; Veras, 2005, 2013). Além das aproximações quanto ao foco no presente e na complexidade da originação dos fenômenos, também podemos identificar 
uma leitura política no movimento budista, sobretudo de forma mais bem delineada e explícita nas contribuições do budismo engajado de Thich Nhat Hanh (1993) e do secularismo de Stephen Batchelor $(1998,2012)$. Podemos remontar as raízes desse vislumbre na própria ênfase dada pela tradição mahayana, cuja centralidade na noção de bodisatva, ou seja, aquele que se ilumina, mas retorna para ajudar aos demais seres na travessia e a alcançarem a mesma condição. O objetivo final inerente ao pensamento mahayana é construir uma sociedade iluminada (Batchelor, 1998; Goto-Jones, 2013; Nhat Hahn, 1993; Styron, 2016).

Ribeiro (2010) afirma que, diante de um contexto pautado estreitamente em uma narrativa científica e que se centra em "problemas" e procura ansiosamente "resolvêlos", uma proposta existencial que enfatize o humano e suas relações, bem como visando entender e respeitar as especificidades de cada ser, como propõe a abordagem gestáltica, provavelmente será rejeitada. Ressalta ainda a importância de sabermos respeitar e trabalhar com as resistências, e não contra elas. Por fim, o autor sustenta a necessidade de conscientização e integração das partes, não havendo razão para optar entre as polaridades dicotômicas de forma maniqueísta, como apontamos anteriormente na proposta goodmaniana. Batchelor (1998) também destaca os polos individuação e engajamento social, para os quais Goodman buscava uma superação, e defende que a comunidade é a ligação entre eles e afirma que a solução não seria gestada por instituições autoritárias ou monolíticas, mas fruto de pequenas comunidades seculares e autônomas fundadas na amizade e na cooperação.

Discorrer detalhadamente sobre distanciamentos e aproximações entre a Gestalt-terapia e a psicologia budista certamente resultaria em um longo texto, talvez um livro ao menos. Entretanto os elementos destacados provavelmente já são referências mínimas para que o leitor possa explorar o tema segundo uma mirada gestáltica. Assim, direcionamo-nos para o debate das implicações do uso de mindfulness segundo a sugestão de Goodman para uma ontologia gestáltica.

\section{O paradoxo da revolução ou além do apocalipse zumbi}

A literatura, a mídia e o cinema frequentemente abordam a temática "zumbis". Diante da "revolução" ofertada pelo movimento de mindfulness ocidental, poderíamos fazer uma analogia com o apocalipse zumbi se considerarmos o afastamento da tecnologia desenvolvida de seus efeitos sociopolíticos. A separação entre técnica e ética produz pessoas "mortas-vivas" ou "quase mortas", que não se contrapõe ao sistema, alienadas de si e do contexto na qual estão inseridas (Han, 2017). De acordo com GotoJones (2013), o "apocalipse zumbi" representaria o medo da iluminação, e os zumbis seriam a resposta da condição humana aprisionada ao capitalismo.

Toda e qualquer produção humana que se proponha modificadora do contexto vigente corre o risco de ser apropriada pelo próprio sistema que recebe tal intervenção e utilizada a favor de sua manutenção. $\mathrm{O}$ capitalismo tardio parece usar apropriações cínicas (tais como a diluição, a pasteurização, por exemplo) como estratégias mais eficazes do que o confronto direto por meio da simples censura/proibição no enfrentamento de discursos e práticas potencialmente subversivos e/ou questionadores do status quo. Todavia algumas modificações e apropriações, igualmente, podem atuar como verdadeiros "cavalos de Tróia". A evolução dos campos não pode ser antecipada, e direções imaginadas podem revelar gargalos e obstáculos não previstos. Tanto forças de conservação como criadoras atuam no campo, conseguindo umas ou outras direcionar mais ou menos o processamento daquilo que se encontra presente.

Como apontamos na introdução deste texto, autores variados veem com restrição o uso da psicologia budista na contemporaneidade, destacando possíveis mazelas de sua instrumentação a fim de promover a alienação. Goto-Jones (2013) vê essa aversão à dissolução do ego e o risco de uma sociedade "pós-humana" zumbi como um posicionamento produzido por uma compreensão parcial das filosofias orientais que sustentam as práticas de mindfulness. De fato, o movimento de mindfulness acabou por abocanhar essa tecnologia e a imputar uma marca, uma identidade comercial de resposta rápida para todo tipo de problema. Todavia, mesmo que muitas práticas se distanciem de suas tradições originais, sejam simplistas e alterem os conceitos originais, os processos de apropriação cultural e produção de outros sentidos são inevitáveis. Num contexto contemporâneo de hibridização pós-secular, parece difícil separar o que é laico e religioso em diversas dimensões da vida cotidiana, uma vez que práticas e fazeres podem ser interpretados e utilizados tanto em situações seculares como religiosas sem grande distinção no seu estilo palpável se não pelo significado que lhes imputamos (Frisk, 2012).

Conforme Goto-Jones, (2013), a revolução na sociedade ocidental contemporânea se apresenta de forma silenciosa e mais pacífica, baseada em padrões de homens brancos e europeus representantes da classe média, levando a crer que a doença da sociedade atual é a "do pensamento". Não se questiona mais a estrutura em que vivemos, mas se medicaliza, culpabiliza e patologiza os sujeitos, produzindo sintomas que são alimentados e controlados pelo próprio sistema capitalista vigente, cuja solução seria a aplicação de métodos e procedimentos individuais. O movimento das terapias baseadas em mindfulness procuraria revelar e resolver um tipo de falsa consciência gerada pela dinâmica do próprio capitalismo (Goto-Jones, 2013). O foco dos estudos científicos a respeito da atenção plena está na comprovação de sua eficácia ou não, sem sugerir questionamentos políticos que caberiam na prática - postura esta da qual discordamos.

Schmidt (2016) levanta duas questões na discussão do uso de mindfulness como política pública de saúde: (1) seria compatível com a neutralidade liberal?; e (2) o foco 
excessivo no aspecto de atenção plena ao aqui-agora poderia esvaziar a discussão de outros fatores (principalmente sociais) que influenciariam negativamente a saúde mental e a qualidade de vida? Como as forças de coerção se tornam mais sutis e sofisticadas (Han, 2017; Ribeiro, 2010), a secularização das "tecnologias do self" e seu esvaziamento ideológico podem ser uma maneira de adaptar os instrumentos disponíveis na psicologia budista para um formato mais tolerável no contexto clínico em sociedades com cultura predominantemente cristã (Goto-Jones, 2013). Apresentar o budismo a partir de uma perspectiva secular ou pós-religional é um risco, pois pode o separar de suas raízes. Por outro lado, a própria apresentação do Dharma por Gautama sem investir na reflexão de aspectos metafísicos permitiu que ele se espalhasse mundo afora por diversas culturas, ganhando diferentes roupagens e se adaptando às culturas que encontrava. Gautama não se deteve em debates metafísicos ou soteriológicos, adotando um posicionamento mais alinhado com o agnosticismo (Batchelor, 1998, 2012; Durazzo, 2015; Frisk, 2012). Batchelor (2012) destaca o aspecto pragmático do Dharma e suas instruções com viés prático para uma comunidade que coopera com o objetivo de que todos possam despertar e se liberar da insatisfação inerente às situações da vida. Lembramos que qualquer abordagem psicoterapêutica é perpassada por aspectos políticos, uma vez que, ao envolver o homem e suas relações, estamos envolvendo também questões sociais (Belmino, 2015), e querer desenvolver uma tecnologia que não transmita qualquer ideologia ou estilo de vida é impraticável (Schmidt, 2016). Dessa forma, todo posicionamento é a defesa de um modus vivendi em detrimento de outro.

Quando a sociedade se configura de forma negativa, se apoiando na falta ao invés da presença, os controles se internalizam e a autoexploração mostra sua eficiência diante da exploração externa. A hegemonia do ideal nunca alcançado ultrapassa a repressão em eficiência: a sedução do ideal e da vontade de mudança não necessita de contínua vigilância do sistema vigente, já que a própria pessoa se cobra um desempenho jamais alcançável. Essa busca autoimposta cria zumbis saudáveis, altamente eficientes, porém mortos em propósitos vivos (Han, 2017), e a oferta demasiada de opções e o esvaziamento de conquistas levam à apatia e à estagnação (Belmino, 2017; Han, 2017). Porém existe uma diferença na dissolução do eu centrado nas perspectivas budista e ocidental, tal que não podemos igualar o meditante mindful e o zumbi mindless (Goto-Jones, 2013).

Ambos, budismo e Gestalt-terapia, consideram dimensões sociais, políticas, econômicas e culturais, não havendo abertura para outra saída senão mudanças para além da individualidade, isto é, a comunidade deveria ser igualmente impactada. Mesmo em outras abordagens psicoterápicas ocidentais encontramos essa premissa, como na argumentação de Fulton e Siegel (2016) sobre o adoecimento e a cura estarem intrinsecamente conectados ao contexto sociocultural em que se vive.
Como a organização social contemporânea se caracteriza pela autocobrança de um ideal de saúde, de prosperidade, bem como de produtividade, exigindo a supressão de todo e qualquer aspecto que denote fragilidade, incapacidade ou descontrole (Han, 2017), é necessário ao sistema vigente livrar-se do fundo ideológico que considera o bemestar amplo e a plena inserção social numa sociedade devidamente sustentável para viabilizar o projeto neoliberal. Dessa forma, práticas de mindfulness que não se restrinjam à atenção focada promoveriam a percepção de formas de alienação e coerção institucionais em vigor, ou seja, atrapalhariam tal proposta ideológica.

Goodman parecia preferir o uso do termo autonomia em vez de liberdade, uma vez que pensar autonomia seria pensar a pessoa em interdependência com a sua história, seu contexto e suas relações (Belmino, 2017; Goodman, 2010a, 2010b; Stoehr, 1994). Considerando tal postura, o trabalho do terapeuta vai além de uma proposta de autoconhecimento individualizante, pois buscaria auxiliar a pessoa a identificar formas de coerção e repressão que se tornaram hábitos e fixaram-se num padrão conservativo acarretando seu sofrimento. Essa evitações que ora são nocivas foram previamente tentativas criativas de ajustamento em dada situação, uma forma de lidar com os conflitos entre o organismo e o ambiente (Belmino, 2017; Perls et al., 1997). Além disso, vale destacar que ser um facilitador de ajustamentos criativos não deve ser confundido com um agente "normalizador", de ajustamento social ou conformação segundo as referências opressoras do sistema vigente. Nesse sentido, o profissional deve levar em consideração a complexidade da vida, mantendo em vista os aspectos sociais, políticos, econômicos, culturais e históricos que permeiam o desenvolvimento humano, a fim de não alienar o paciente no esvaziamento dessas dimensões. A psicologia budista e a Gestalt-terapia não culpabilizam a pessoa como único "causador" de seu sofrimento e adoecimento, mas buscam auxiliar no reconhecimento da originação interdependente dos fenômenos. Essa é uma postura de responsabilização, de retomada da participação ativa em sociedade e de reapropriação dos condicionantes.

Voltando aos autores que criticam o crescimento do movimento de mindfulness como prelúdio a um apocalipse zumbi, mencionados na introdução deste artigo, é importante a crítica das tecnologias de saúde que tenham como ideal (ou ideário) adaptar o sujeito para que tolere as condições políticas, sociais e econômicas, alijando-o de reflexões sobre aspectos estruturais ou oferecendo soluções simplórias para seu sofrimento. Acreditamos que as sociedades podem encontrar uma forma de equilibrar as necessidades pessoais e coletivas. Não é uma tarefa fácil, talvez até utópica, haja vista que exige negociação e descentralização, como previsto por Goodman (1991, 2010a, 2010b), e uma nova compreensão de self para tal emancipação radical (Goto-Jones 2013). Quando cidadãos cultivam a atitude de estar presente e reconhecem a necessidade do outro, os esforços desse engajamento ativo podem levar ao bem-estar, à felicidade, 
à harmonia e à paz (Batchelor, 1998; Nhat Hahn, 1993; Styron, 2016). Reconhecer como estamos agora e nossa interdependência nas dimensões individual, societal e ecológica, em vez de tentarmos caber na cama de Procusto, seria uma revolução paradoxal.

\section{Considerações finais}

Este estudo teve como proposta apresentar uma breve discussão a partir da abordagem gestáltica a respeito da utilização de um arcabouço cultural e tecnológico budista, em especial nas práticas de mindfulness contemporaneamente. Com isso, buscamos promover uma reflexão acerca da apropriação e banalização de conhecimentos milenares e seu emprego sem o devido reconhecimento de seus pressupostos histórico-filosóficos ou considerar desdobramentos sociais e políticos. Resgatamos um pouco da história da tradição budista e suas propostas de resolução do sofrimento humano, o qual seria proveniente da própria mente e de nossa relação conosco mesmos e com o mundo. A metodologia para a extinção do sofrimento humano, o Caminho Óctuplo, compreende a prática da meditação como um dos oito aspectos interdependentes de liberação. As práticas budistas têm sido adaptadas e pesquisadas por diversos profissionais de saúde desde meados da década de 1970, sendo o MBSR de Jon KabatZinn, o percursor de diversos programas e protocolos desenvolvidos para populações diversas.

Observamos uma massificação e banalização das práticas tradicionais ao longo dos anos, bem como seu distanciamento do fundo cultural e ideológico de origem e sua utilização para fins questionáveis e como instrumento de alienação e exclusão ao invés de integração e inclusão social. O resultado que se percebe é que, em vez do estímulo à autonomia, ao engajamento consciente e à retomada do papel de cidadão, as técnicas são usadas como ferramenta de individualização, dissociação, alienação, docilização e normatização da subjetividade mascarada no discurso de autocuidado, superação e eficiência do capitalismo tardio.

Em diálogo com o referencial teórico da Gestaltterapia, destacamos o interesse da abordagem pela capacidade do indivíduo em estar atento aos fenômenos que emergem a sua volta, assim como no estabelecimento de relações conscientes com o meio. Paul Goodman, por sua vez, com seu profundo envolvimento nas questões sociais e políticas que atravessam a natureza humana e fervilham na geração pós-Segunda Guerra, contribuiu para o desenvolvimento de uma ontologia gestáltica, aprofundando a discussão do potencial humano e buscando, por meio de ajustamentos criativos e criadores, possíveis saídas para os mecanismos coercitivos e centralizadores do sistema organizado. Apresentamos também algumas influências da psicologia budista na Gestalt-terapia, sobretudo quanto ao foco no momento presente, numa compreensão de campo fenomenal e existencial interdependente amplo e numa leitura crítica dos aspectos políticos que lhes são inerentes.

Há, certamente, aproximações e afastamentos entre a Gestalt-terapia e a psicologia budista, ponto este que merece mais atenção da comunidade gestáltica, haja vista as possíveis contribuições de se retomar uma base filosófica que faz parte das raízes de nossa abordagem. Também nos parece prematuro avaliar a apropriação de práticas meditativas como algo revolucionário ou temerário, mesmo que haja fortes indícios de que ela seja, em boa parte, a partir de uma postura colonialista e inapropriada. Portanto destacamos que, a despeito do que parece uma crescente produção crítica internacional, não encontramos literatura brasileira que analise o movimento de mindfulness contemporâneo com esta mirada, de modo que convidamos a comunidade científica brasileira para este debate.

\section{Buddhist revolution or zombie apocalypse? Discussions on mindfulness from a gestalt perspective}

Abstract: While the search for Eastern meditative practices as health and quality of life technology has increased significantly in recent years, the lack of understanding regarding core concepts and values from which such techniques emerge produces proposals that can be either revolutionary or dystopic. This text proposes a brief discussion concerning the mindfulness movement based on Goodman's gestalt. Thus, we (a) briefly present the transmission of these practices from Buddhist traditions to contemporary Western science; (b) highlight some theoretical aspects that bring gestalt-therapy closer to and distance it from Buddhist premises; and (c) discuss the appropriation of such traditions, their values and technologies by a utilitarian neoliberal paradigm.

Keywords: mindfulness, gestalt therapy, ideology, mental health, politics.

\section{Révolution bouddhiste ou apocalypse zombie? Discussions sur la pleine conscience du point de vue de la gestalt-thérapie}

Résumé : Alors que la recherche de pratiques méditatives orientales comme technologie de santé et de la qualité de vie s'est considérablement accrue ces dernières années, le manque de compréhension des concepts et valeurs fondamentales dont émergent ces techniques produit des propositions qui peuvent être soit révolutionnaires, soit dystopiques. Ce texte propose une 
brève discussion sur le mouvement de pleine conscience basée sur la gestalt-thérapie de Goodman. Ainsi, nous (a) présentons brièvement la transmission de ces pratiques des traditions bouddhistes à la science occidentale contemporaine ; (b) soulignons certains aspects théoriques qui rapprochent et éloignent la gestalt-thérapie des prémisses bouddhistes; et (c) discutons de l'appropriation de ces traditions, de leurs valeurs et de leurs technologies par un paradigme néolibéral utilitaire.

Mots-clés : pleine conscience, gestalt-thérapie, idéologie, santé mentale, politique.

\section{¿Revolución budista o apocalipsis zombi? Debates sobre la atención plena desde una perspectiva gestáltica}

Resumen: La búsqueda de prácticas meditativas orientales como herramienta de salud y calidad de vida ha aumentado significativamente en los últimos años. Sin embargo, la falta de comprensión de los conceptos y valores centrales de los cuales surgen tales técnicas produce propuestas que pueden ser revolucionarias o distópicas. En este texto proponemos hacer una breve discusión sobre el movimiento de la atención plena desde una perspectiva gestáltica goodmaniana. Así, (a) presentamos brevemente la transmisión de estas prácticas desde las tradiciones budistas hasta la ciencia occidental contemporánea; (b) destacamos algunos aspectos teóricos que acercan y alejan la terapia gestalt de las referencias budistas; y (c) discutimos la apropiación de estas tradiciones, sus valores y tecnologías por un paradigma neoliberal utilitario.

Palabras clave: atención plena, terapia gestalt, ideología, salud mental, política.

\section{Referências}

Barrett, W. (1956). Zen for the West. In D. T. Suzuki, Zen Buddhism: selected writings of D.T. Suzuki (pp. vii-xx). Garden City: Doubleday Anchor Books.

Batchelor, S. (1998). Buddhism without beliefs. New York: Riverhead Books.

Batchelor, S. (2012). A secular Buddhism. Journal of Global Buddhism, 13, 87-107. Recuperado dehttps://bit.ly/2XmhGgz

Belmino, M. C. (2015). Os vários desdobramentos da Gestaltterapia: de onde partimos? In M. C. Belmino (Ed.), Gestalt-terapia e atenção psicossocial (pp. 36-59). Fortaleza, CE: Premius.

Belmino, M. C. (2017). A ontologiagestáltica de Paul Goodman e seus desdobramentos clínicos, politicos e educacionais: gestalt-terapia, anarquia e desescolarização. Rio de Janeiro, RJ: Via Verita.

Belmino, M. C. B. (2018). Fritz Perls e Paul Goodman: duas faces da Gestalt-terapia. Rio de Janeiro, RJ: Via Verita.

Brazier, D. (2016). Mindfulness: traditional and utilitarian. In R. Purser, D. Forbes, \& A. Burke (Eds.), Handbook of mindfulness: mindfulness in behavioral health (pp. 6374). Cham: Springer.

Brown, C. G. (2016). Can "secular" mindfulness be separated from religion? In R. Purser, D. Forbes, \& A. Burke (Eds.), Handbook of mindfulness: mindfulness in behavioral health (pp 75-94). Cham: Springer.

Cebolla, A., \& Demarzo, M. (2016). O que é mindfulness? In A. C. Martí, J. García-Campayo, \& M. Demarzo (Eds.), Mindfulness e ciência: da tradição à modernidade (pp. 19-36). São Paulo, SP: Palas Athena.

Demarzo, M., \& Campayo, J. G. (2015). Manual prático de mindfulness: curiosidade e aceitação. São Paulo, SP: Palas Athena.
Diniz, A. M. A. (2010). Surgimento e dispersão do budismo no mundo. Espaço e Cultura, 27, 89-105. Recuperado de https://bit.ly/3ANs937

Doran, P. (2018, February 26). Mindfulness is just Buddhism sold to you by neoliberals. Recuperado de https://bit.ly/3iQmsLG

Durazzo, L. (2015). Perspectiva pós-religional e budismo secular: Stephen Batchelor e a religião pós-metafísica. Horizonte: Revista de Estudos de Teologiae Ciências da Religião, 13(37), 592-604. doi: 10.5752/P.2175-5841.2015v13n37p592

Frazão, L. M. (2013). Um pouco da história... um pouco dos bastidores. In L. M. Frazão \& K. O. Fukumitsu (Eds.), Gestalt-terapia: fundamentos epistemológicos e influências filosóficas (pp. 11-23). São Paulo, SP: Summus.

Frisk, L. (2012). The practice of mindfulness: from Buddhism to secular mainstream in a post-secular society. Scripta Instituti Donneriani Aboensis, 24, 48-61. Recuperado de https://bit.ly/2UlYRZN

Fulton, P. R., \& Siegel, R. D. (2016). Psicologia budista e psicologia ocidental: buscando pontos em comum. In C. K. Germer, R. D. Siegel, \& P. R. Fulton (Eds.), Mindfulness e psicoterapia (pp. 37-58). Porto Alegre, RS: Artmed.

Germer, C. K. (2016). Mindfulness - o que é? Qual é a sua importância? In C. K. Germer, R. D. Siegel, \& P. R. Fulton (Eds.), Mindfulness e psicoterapia (pp. 2-36). Porto Alegre, RS: Artmed.

Girard, T. V. G., \& Feix, L. F. (2016). Mindfulness: concepções teóricas e aplicações clínicas. Higia: Revista das Ciências da Saúde do Oeste Baiano, 1(2), 94-124.

Gold, E., \& Zahm, S. (2018). Buddhist psychology \& Gestalt therapy integrated: psychotherapy for the $21^{\text {st }}$ century. Portland: Metta Press. 
Goodman, P. (1991). My psychology as a "utopian sociologist". In T. Stoehr (Ed.), Nature Heals: psychological essays of Paul Goodman (pp. 226-232). Highland: The Gestalt Journal Press.

Goodman, P. (2010a). Some prima facie objections to decentralism. In T. Stoehr (Ed.), Drawing the line once again: Paul Goodman's anarchist writings (pp. 75-88). Oakland: PM Press.

Goodman, P. (2010b). The May pamphlet. In T. Stoehr (Ed.), Drawing the line once again: Paul Goodman's anarchist writings (pp. 21-54). Oakland: PM Press.

Goto-Jones, C. (2013). Zombie apocalypse as mindfulness manifesto (after Žižek). Postmodern Culture, 24(1). Recuperado de https://muse.jhu.edu/article/567227

Han, B.-C. (2017). Sociedade do cansaço. Petrópolis, RJ: Vozes.

Joyce, P., \& Sills, C. (2016). Técnicas em Gestalt: aconselhamento e psicoterapia. Petrópolis, RJ: Vozes.

Juliano, J. (2004). Gestalt-terapia: revisitando as nossas histórias. Revista IGT na Rede, 1(1). Recuperado de https://bit.ly/3ARKRGZ

Kabat-Zinn, J. (2011). Some reflections on the origins of MBSR, skillful means, and the trouble with maps. Contemporary Buddhism, 12(1), 281-306. doi: 10.1080/14639947.2011.564844

Kabat-Zinn, J. (2017). Atenção plena para iniciantes. Rio de Janeiro, RJ: Sextante.

Naranjo, C. (1980). Centralidade no presente: técnica, prescrição e ideal. In J. Fagan \& I. L. Shepherd (Eds.), Gestalt-terapia: teoria, técnicas e aplicações (4a ed., pp. 17-78). Rio de Janeiro, RJ: Zahar.

Naranjo, C. (2005). Entre meditação e psicoterapia. Petrópolis, RJ: Vozes.

Naranjo, C. (2013). La vieja y novíssima Gestalt: actitud y práctica de un experiencialismo ateórico. Santiago: Cuatro Vientos.

Nhat Hahn, T. (1993). Paz a cada passo: como manter a mente desperta em seu dia-a-dia. Rio de Janeiro, RJ: Rocco.

Olendzki, A. (2012). Buddhist psychology. In S. R. Segall (Ed.), Encountering Buddhism: western psychology and Buddhist teachings (pp. 9-30). New York: Suny Press.

Olendzki, A. (2016). Glossário de termos em psicologia budista. In C. K. Germer, R. D. Siegel, \& P. R. Fulton (Eds.), Mindfulness e psicoterapia (pp. 319-327). Porto Alegre, RS: Artmed.

Perls, L. (1994). Vivendo en los límites. Valencia: Promolibro.

Perls, F., Hefferline, R., \& Goodman, P. (1997). Gestaltterapia. São Paulo, SP: Summus.

Prestrelo, E. T., \& Quadros, L. C. T. (2009). Abordagem gestáltica: um resgate da dimensão sensível do humano. Estudos e Pesquisas em Psicologia, 9(1), 10-15. Recuperado de https://bit.ly/2XAjqmG

Purser, R. (2019, June 14). The mindfulness conspiracy. Recuperado de https://bit.ly/3gduVqF

Ribeiro, W. F. R. (2010). Da dificuldade de conversão à mentalidade gestáltica. Revista da Abordagem Gestáltica, 16(1), 85-90. Recuperado de https://bit.ly/3mc8mGE
Rosmaninho, M. T. (2010). Tornar-se terapeuta: a prática da meditação na formação do psicólogo clínico de orientação fenomenológica [Dissertação de Mestrado]. Pontifícia Universidade Católica de São Paulo, São Paulo, SP.

Sá, L. F. C., Jr. (2009). Paul Goodman e os outros caminhos da Gestalt. Revista IGT na Rede, 6(11), 243-264. Recuperado de https://bit.ly/3g7PUeb

Schmidt, A. T. (2016). The ethics and politics of mindfulnessbased interventions. Journal of Medical Ethics, 42(7), 450-454. Recuperado de https://bit.ly/3xPZdFO

Scott, D., \& Doubleday, T. (2001). O livro de ouro do Zen: a sabedoria milenar e sua prática $(2 \mathrm{a}$ ed.). Rio de Janeiro, RJ: Ediouro.

Sousa, L. M. M., Firmino, C. F., Marques-Vieira, C. M. A., Severino, S. S. P., \& Pestana, H. C. F. C. (2018). Revisões da literatura científica: tipos, métodos e aplicações em enfermagem. Revista Portuguesa de Enfermagem de Reabilitação, 1(1), 45-54. Recuperado de: https://bit.ly/3mh6DQt

Spagnuolo Lobb, M. (2013). The now-for-next in psychotherapy: Gestalt therapy recounted in postmodern society. Milan: Franco Angeli.

Stoehr, T. (1991). Introduction. In T. Stoehr (Ed.), Nature heals: - the psychological essays of Paul Goodman (pp. ix-xxiv). Gouldsboro: The Gestalt Journal Press.

Stoehr, T. (1994). Here now next: Paul Goodman and the origins of Gestalt therapy. New York: Routledge.

Styron, C. W. (2016) Psicologia positiva e o caminho bodhisattva. In C. K. Germer, R. D. Siegel, \& P. R. Fulton (Eds.), Mindfulness e psicoterapia (pp. 304-317). Porto Alegre, RS: Artmed.

Tomassini, M. (2016). Mindfulness in working life. Beyond the "corporate" view, in search for new spaces of awareness and equanimity. In R. Purser, D. Forbes, \& A. Burke (Eds.), Handbook of mindfulness: Mindfulness in behavioral health (pp. 215-230). Cham: Springer.

Veras, R. P. (2005). Ilumina-ação: diálogos entre a gestaltterapia e o zen-budismo [Dissertação de Mestrado]. Pontifícia Universidade Católica de São Paulo, São Paulo, SP.

Veras, R. P. (2013). A influência do pensamento oriental na Gestalt-terapia. In L. M. Frazão \& K. O. Fukumitsu (Eds.), Gestalt-terapia: fundamentos epistemológicos e influências filosóficas (pp. 157-177). São Paulo, SP: Summus.

Vosgerau, D. S. S., \& Romanowski, J. P. (2014). Estudos de revisão: implicações conceituais e metodológicas. Revista Diálogo Educacional, 14(41), 165-189. doi: 10.7213/dialogo.educ.14.041.DS08

Žižek, S. (2012, 10 de agosto). The buddhist ethic and the spirit of global capitalism. Recuperado de https://zizek.uk/ the-buddhist-ethic-and-the-spirit-of-global-capitalism/

Recebido: $29 / 08 / 2020$ Aprovado: 30/07/2021 